\title{
The gyre-scale circulation of the North Atlantic and sea level at Brest
}

\author{
P. L. Woodworth ${ }^{1}$, N. Pouvreau ${ }^{2}$, and G. Wöppelmann ${ }^{3}$ \\ ${ }^{1}$ Proudman Oceanographic Laboratory, Joseph Proudman Building, 6 Brownlow Street, Liverpool L3 5DA, UK \\ ${ }^{2}$ UMR 5566 LEGOS-CNES, 14 av. Edouard Belin, 31400 Toulouse, France \\ ${ }^{3}$ UMR 6250 LIENSs, Université de La Rochelle - CNRS, 2 rue Olympe de Gouges, 17000 La Rochelle, France
}

Received: 10 September 2009 - Published in Ocean Sci. Discuss.: 16 October 2009

Revised: 13 January 2010 - Accepted: 29 January 2010 - Published: 8 February 2010

\begin{abstract}
The relationship between the gyre-scale circulation of the North Atlantic, represented by air pressure near to the centre of the sub-tropical gyre, and sea level measured at the eastern boundary of the ocean has been investigated using records commencing in the middle of the 18th century. These time series are twice as long as those employed in an earlier study of this relationship. Near-continuous values of annual mean sea level and mean high water from Brest, and air pressure fields for the eastern North Atlantic derived from terrestrial instrumental pressure records and ship logbook information, have been used to demonstrate that sea level on the eastern boundary does indeed appear to be related to air pressure at the centre of the gyre (subject to reservations concerning short sub-sections of data near to the ends of the records). These findings confirm the earlier conclusions but over much longer timescales. This relationship can explain at least part of the century timescale accelerations in European sea level records obtained from tide gauge and saltmarsh data. This finding has important implications for interpretation of the observed sea level rise and acceleration on the European Atlantic coast, suggesting that redistribution of water could play an important role instead of (or as well as) change in ocean volume.
\end{abstract}

\section{Introduction}

In an interesting recent paper, Miller and Douglas (2007) pointed to a possible link between the strength of the atmospheric and oceanic gyre-scale circulation of the North Atlantic and sea levels measured at its eastern boundary. It is well known that the longer European Atlantic tide gauge records, which span the last one and half centuries or more,

Correspondence to: P. L. Woodworth (plw@pol.ac.uk) provide evidence for increasing sea levels. In addition, they suggest a century-timescale acceleration with higher rates of rise in the 20th century than previously. Liverpool and Sheerness in the UK (Woodworth, 1999), Brest in France (Wöppelmann et al., 2008), and Cascais in Portugal are among these stations. Similar trends and accelerations have also been observed in European saltmarsh data (e.g. Leorri et al., 2008).

A similar acceleration can also be seen in records from the eastern boundary of the North Pacific, notably at San Francisco. From analysis of sea surface air pressure fields, and of station air pressures from the Azores, Miller and Douglas (2007) were able to provide evidence for a deceleration in North Atlantic gyre strength (spin down), represented by decreasing air pressures near to the centre of the sub-tropical gyre, and for a connection to an acceleration in the rate of sea level change at the eastern boundary. A similar inference was made from the North Pacific data, although the poorer quality air pressure fields available for that ocean prevented as firm a set of conclusions as for the North Atlantic.

The Miller and Douglas (2007) analysis was limited as it dealt with sea level and air pressure changes on century timescales using data sets that spanned little more than a century themselves (i.e. $\sim 1880$ onwards). However, it had important implications with regard to our understanding of whether the changes observed at the eastern boundary are simply due to redistribution of water, rather than (or as well as) thermal expansion and addition of new water from the cryosphere and hydrosphere, as is the general current understanding of sea level rise (e.g. Bindoff et al., 2007). This possibility necessitates further investigation with the use of sea level and air pressure data sets spanning a longer period.

In this paper, we present a similar analysis for the North Atlantic to that of Miller and Douglas (2007), but use sea level and air pressure records twice as long as those used previously. The research has been made possible through an immense amount of recent "data archaeology", wherein

Published by Copernicus Publications on behalf of the European Geosciences Union. 


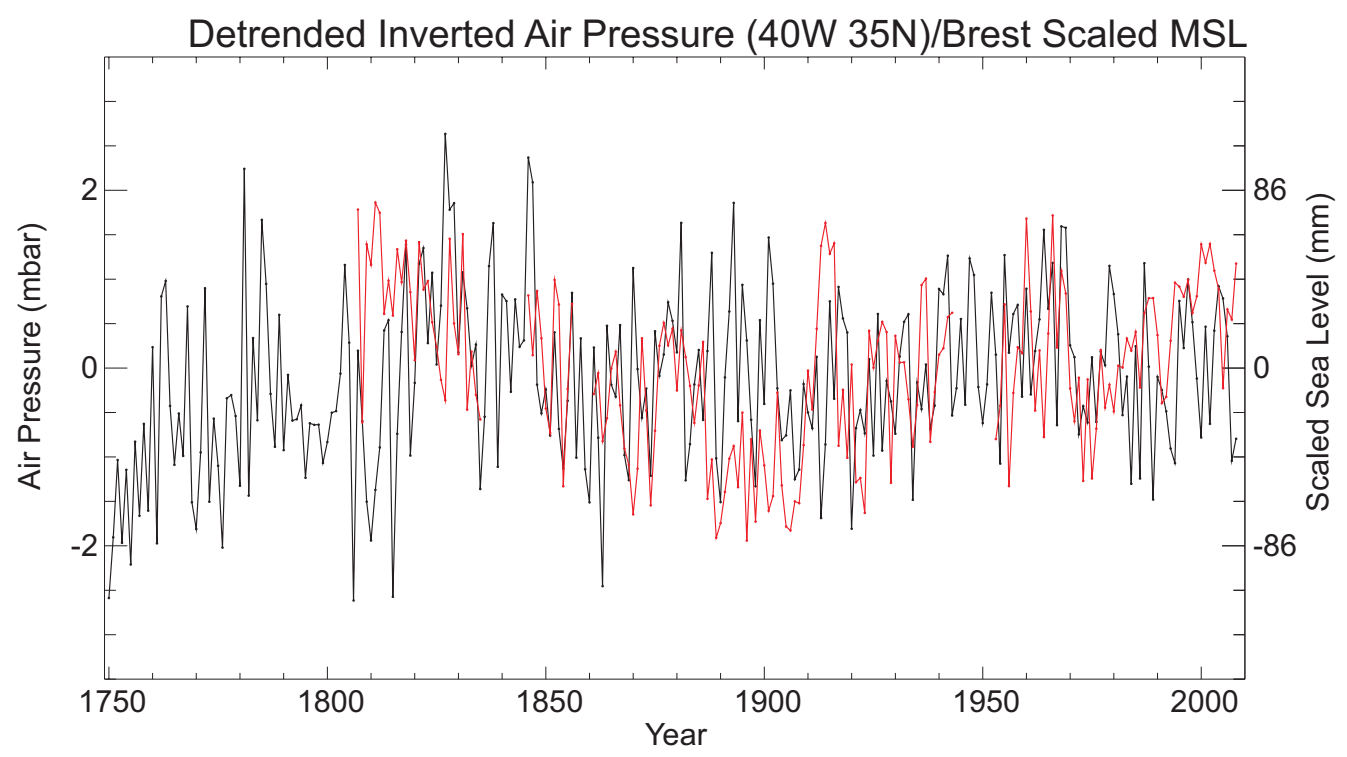

Fig. 1. Annual mean air pressure at $40^{\circ} \mathrm{W}, 35^{\circ} \mathrm{N}$ from the dataset of Küttel et al. (2009) shown in black, and annual mean MSL measured at Brest shown in red (the former measured Dec-Nov, the latter for calendar years). The air pressures have been multiplied by -1 so as to correspond to sea level change. Both records have been detrended using a baseline period of 1807 onwards.

valuable historical records have been rediscovered and their data converted into computer form and quality controlled. The sea level record of Brest, comprising several years of measurements in the late 17th and early 18th centuries, mean high waters (MHWs) from the middle of the 18th century, and mean sea levels (MSLs) from 1807 constitutes the most extensive set of sea level information from a single location on the European Atlantic coast (Table 1 of Wöppelmann et al., 2006; Pouvreau, 2008). In addition, oceanic air pressure fields have been extended both spatially and temporally with the use of ship logbook information, with the result that annual mean air pressure fields with useful skill have become available for the eastern North Atlantic from 1750 (Küttel et al., 2009 and see information therein on other air pressure reconstruction projects).

Miller and Douglas (2007) focused on the sea level data from Cascais $\left(39^{\circ} \mathrm{N}\right)$, which starts in 1882 , rather than from Brest $\left(48^{\circ} \mathrm{N}\right)$, probably because the latitude of the former is closer to that of the centre of the sub-tropical gyre. However, the low-frequency character of sea level variability at the two sites is similar (see their Fig. 1). Therefore, while Brest may be located further north than ideal, the availability of its long record more than makes up for any possibly reduced gyrerelated signal compared to that at Cascais.

\section{Data and findings}

The air pressure reconstructions of Küttel et al. (2009) are based on terrestrial instrumental pressure records and marine wind information from ship logbooks. Seasonal fields (DJF, MAM, JJA, SON) are available on a $5 \times 5^{\circ}$ grid cov- ering the eastern North Atlantic, Europe and the Mediterranean from $70-20^{\circ} \mathrm{N}$ and $40^{\circ} \mathrm{W}-50^{\circ} \mathrm{E}$ (www.ncdc.noaa. gov/paleo/paleo.html). They have been calculated up to 1886 and thereafter are joined to air pressure fields on the same grid derived from the global HadSLP2 data set based on conventional station pressures (Allan and Ansell, 2006; hadobs. metoffice.com/hadslp2/). Figure 1 shows annual mean air pressure at $40^{\circ} \mathrm{W} 35^{\circ} \mathrm{N}$, which is close to the centre of the spatial Empirical Orthogonal Function-1 (EOF-1) of North Atlantic air pressure variability discussed by Miller and Douglas (2007), and also near to the Azores from which those authors employed a station air pressure time series. This location is at the edge of the reconstruction region of Küttel et al. (2009). Nevertheless, the reconstructions have been shown to provide a good representation of the Atlantic large scale circulation, and tests have been made in the reconstruction process which show that estimates of the strength of the circulation should present significant skill, even during the 18th century (Fig. 4 of Küttel et al., 2009). The air pressure time series has been detrended over the period of 1807 onwards, which corresponds to the availability of MSL information discussed below.

Figure 1 also includes values of MSL for Brest for 1807 onwards extracted from the Revised Local Reference dataset of the Permanent Service for Mean Sea Level (PSMSL, www.pol.ac.uk/psmsl). Values between 1807 and 1835 are derived from Mean Tide Level (MTL), rather than true MSL, and have been adjusted by $29 \mathrm{~mm}$ to make them consistent with the later MSL values (Bouquet de la Grye, 1890; Pouvreau, 2008). The annual mean time series has been detrended over its record length, its average has been aligned with that of the $40^{\circ} \mathrm{W} 35^{\circ} \mathrm{N}$ air pressure for 1807 onwards, 


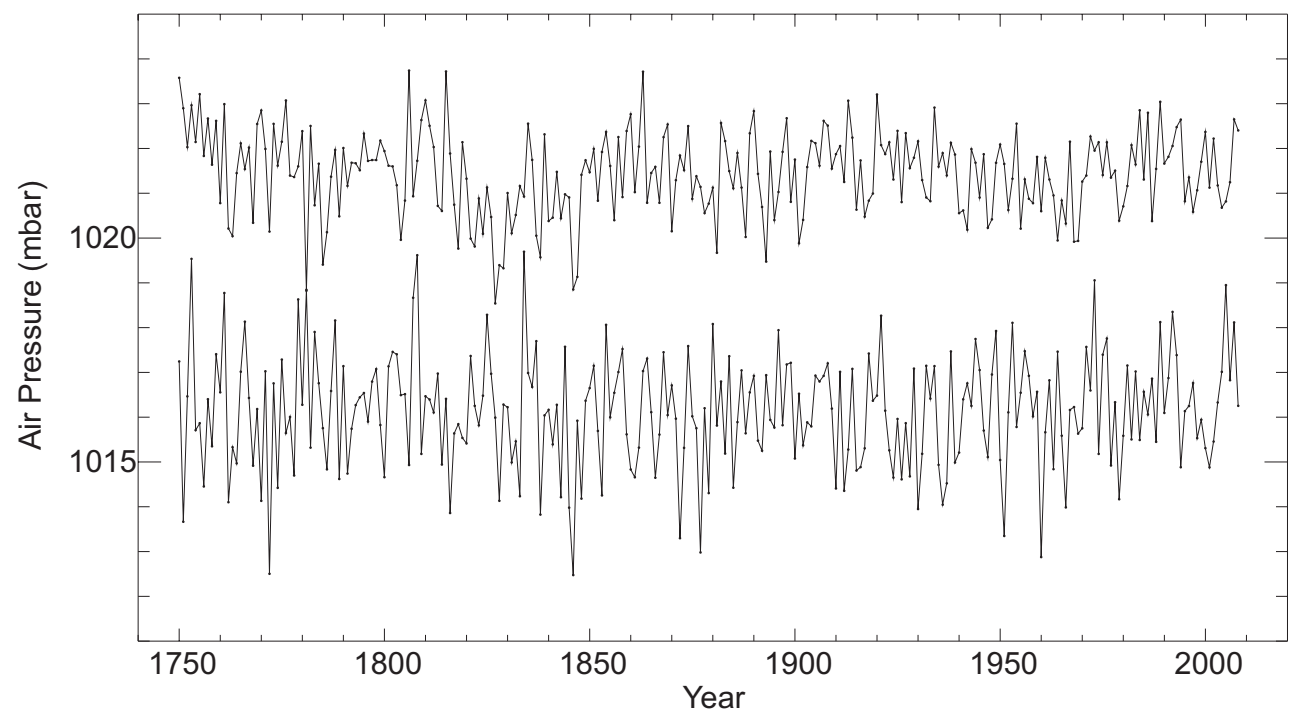

Fig. 2. Time series of annual mean air pressure at $40^{\circ} \mathrm{W} 35^{\circ} \mathrm{N}$ and at $5^{\circ} \mathrm{W} 50^{\circ} \mathrm{N}$ (the nearest grid position to Brest $4^{\circ} 30^{\prime} \mathrm{W} 48^{\circ} 23^{\prime} \mathrm{N}$ ) shown top and bottom respectively, taken from the data set of Küttel et al. (2009).

and for presentation purposes in Fig. 1 its variability has been scaled such that its standard deviation equals that of the air pressure in the same period. The scaling factor (the ratio of the standard deviations of MSL and air pressure) amounts to $0.0233 \mathrm{mbar} / \mathrm{mm}$ which is a similar factor to that obtained by Miller and Douglas (2007).

If one looks first at the period 1880 onwards, which corresponds to the period studied by Miller and Douglas (2007), an overall positive acceleration can be seen in both quantities, with a fall from 1880 to the early 1890 s followed by a rise to about 1960 (punctuated by a particularly large several year enhancement in sea level around 1914) and another fall or flattening off thereafter (see also Woodworth et al., 2009a). However, from the longer records now available, one can see that the post-1880 fall was part of a long term decrease during the 19th century, with the possible exception of some decadal variability around 1880 (the undetrended Brest MSL record being essentially flat during this century). Therefore, the 19th and 20th centuries present two quite different periods of change in both quantities.

It is important to stress (as Miller and Douglas did) that this relationship between sea level and air pressure has nothing to do with the conventional "inverse barometer (IB)" model of $+/-1 \mathrm{~cm}$ change in sea level for a $-/+1$ mbar air pressure change. If one adjusts the MSL record for local air pressure assuming an IB response, then almost the same scaling factor with $40^{\circ} \mathrm{W} 35^{\circ} \mathrm{N}$ air pressure is obtained. The conventional IB model is anyway known not to be appropriate for the eastern boundary at interannual and decadal timescales. Empirical estimates of effective local IB coefficient gives values several times that of the IB (Miller and Douglas, 2007; Woodworth et al., 2009b). One must also note that, while the EOF-1 of North Atlantic sea level pressure variability extends as far as Cascais and Brest (Fig. 2 of
Miller and Douglas, 2007), it represents only a small part of air pressure variance at the eastern boundary. Figure 2 shows that the air pressure at $40^{\circ} \mathrm{W} 35^{\circ} \mathrm{N}$ and at Brest are dissimilar and a correlation between the two sets of annual means gives a coefficient of only 0.14 .

One can extend the analysis even further back in time by making use of MHW data from Brest from the 18th century. These values were measured to the same datum as the later MTL and MSL values (the Zéro Hydrographique). One can employ a MHW time series as quasi-MSL information if the large nodal signals in the record can be removed and if an adjustment can be made for average MHW-MSL. An implicit assumption is that low-frequency sea level signals of interest manifest themselves similarly in both MHW and MSL. The electronic supplement (http://www.ocean-sci.net/6/185/ 2010/os-6-185-2010-supplement.zip) to this paper provides the Brest MHW time series used in this study together with a short section of earlier data from the beginning of the 18th century.

Two methods were used to obtain the quasi-MSL. In the first method, the differences between MHW (slightly smoothed as described by Wöppelmann et al., 2008) and MSL for the post-1807 period, when both quantities were available, were parameterised by a nodal sinusoidal term plus an offset. This parameterisation was then applied to the MHW data from the 18th century in order to derive estimates of MSL. In the second method, a tidal prediction based on best knowledge of the tide at Brest was subtracted from each individual measured high water level, with the annual mean residuals defined to be quasi-MSL (Pouvreau, 2008, chapter 8; Pouvreau et al., 2010). The two methods yield almost identical results and so only those from the second method will be shown here. 


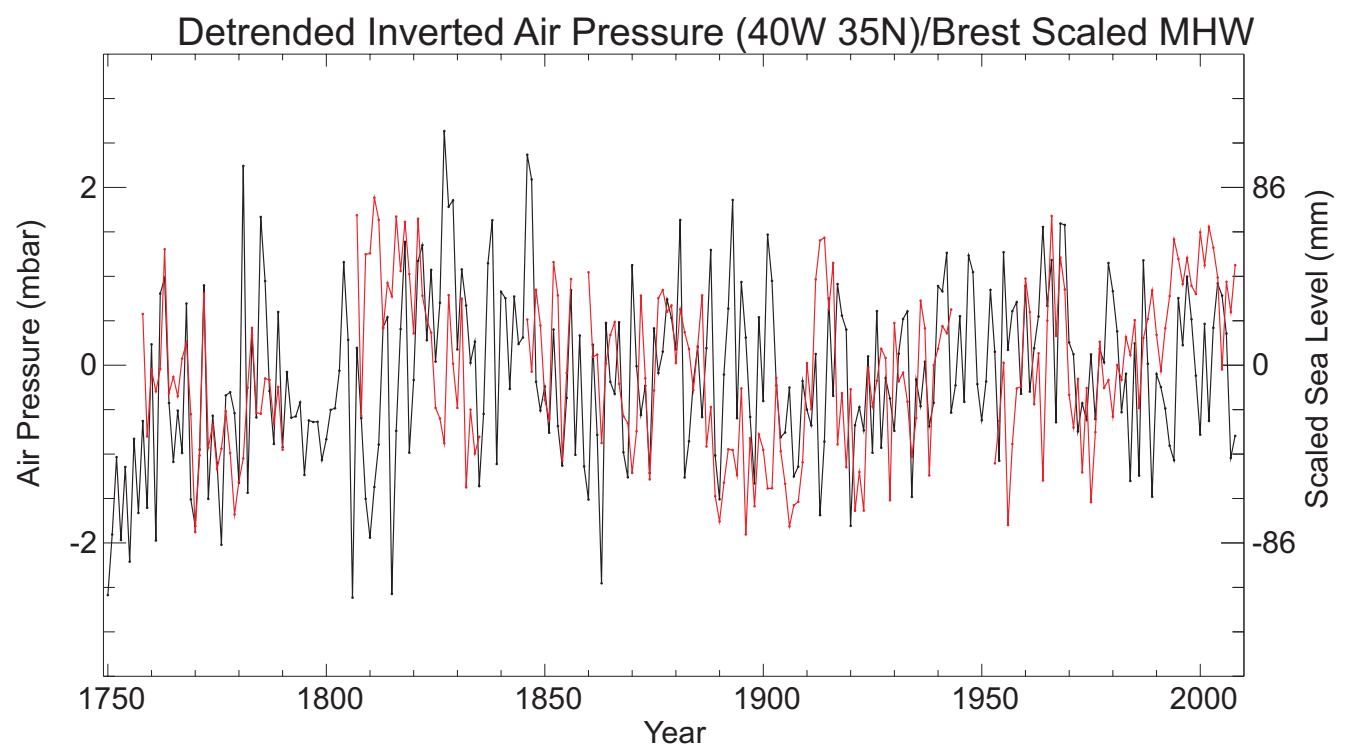

Fig. 3. As for Fig. 1 but using a time series of quasi-MSL at Brest derived from MHW information.

Figure 3 shows the same air pressure data plus the quasiMSL information detrended and scaled as for MSL in Fig. 1 (an almost identical scaling factor of $0.0232 \mathrm{mbar} / \mathrm{mm}$ ). It can be seen that the quasi-MSL does not always successfully simulate true MSL, but that most of the low-frequency signals of the 19th and 20th centuries are reproduced. The extension to the 18th century can be seen to have been most useful in providing an earlier period with low-frequency air pressure signals that are again also represented in the sea level record. In particular, the negative trend in both quantities during most of the 19th century can be seen not to apply in the 18th century. (Tsimplis (2009) pointed to the similarity of the time series in this figure with the North Atlantic Oscillation reconstruction of Luterbacher et al. (2002) which was based on terrestrial air pressure information, and was employed in a study of historical Mediterranean Sea levels by Gomis et al. (2006). Such similarities are quite plausible given that the same large scale meteorological fields are under investigation.)

There are two sub-sections of approximately two decades each which do not correspond well in Fig. 3. The first subsection includes data from 1807 to 1811 which are questionable as the record shows that "the observer of the tides was doing his job wrongly". In addition, high waters between 1812 and 1822 are known to be highly imprecise because of problems with the stone tide staff used (Pouvreau, 2008; Pouvreau et al., 2010). The second sub-section includes recent data since the late 1970s. Inspection of Figs. 1a, b of Miller and Douglas (2007) suggests that this could be one period in which Cascais would be a more suitable choice than Brest.
We have omitted so far to state formal estimates of the similarity or degree of correlation between sea level and air pressure (we note that Miller and Douglas (2007) avoided giving correlations completely). That is because we wished the reader to form his own impression of what appears to us to be a remarkable correspondence between the two quantities on century timescales as shown in Figs. 1 and 3. In order to compare the records at the lowest frequencies (i.e. century timescales), we made low-degree polynomial fits to the two records in Fig. 3 using data from 1807-onwards (for which the records have zero linear trend by construction) and omitting data from the two sub-sections mentioned above where agreement appeared poorest (i.e. we omitted 19th century data for 1818 and earlier and values for 1980 onwards). The inclusion or exclusion of these years of data, located at each end of the record, has a major effect on the determined polynomial coefficients (as is quite clear from inspection of Fig. 3). For the sea level record, a quadratic coefficient of $9.02 \pm 3.4510^{-5} \mathrm{mbar} / \mathrm{year}{ }^{2}$ was obtained corresponding, after the $0.0232 \mathrm{mbar} / \mathrm{mm}$ scaling, to $0.38 \pm 0.15 \mathrm{~mm} /$ year per century, similar to the quadratic coefficients obtained for 19th-20th century "accelerations" derived from other long European sea level records (e.g. Woodworth, 1999). For the inverted air pressure record, the corresponding coefficient was $13.58 \pm 3.5510^{-5} \mathrm{mbar} / \mathrm{year}^{2}$ which is similar to that obtained for sea level. Inclusion of the omitted data results in quadratic coefficients of 14.8 and $1.4510^{-5} \mathrm{mbar} \mathrm{year}^{2}$ for sea level and inverted air pressure respectively, the former being similar to that obtained previously but the latter suggesting almost no quadratic component.

If one applies low-degree polynomial fits to the complete records, so as to include 18th century data, then it is clear from Fig. 3 that one must also consider cubic components. Data for both parameters at the start of the 19th century and 
for recent years were omitted, as before, and air pressure information during the large gap in the sea level record at the end of the 18th century was also excluded. The cubic coefficients obtained were 6.18 and $11.9910^{-7} \mathrm{mbar} / \mathrm{year}^{3}$ for sea level and inverted air pressure respectively. Inclusion of the omitted data strengthened the cubic component of the fit to the sea level record while reducing that for inverted air pressure, the coefficients being 11.03 and $3.1110^{-7}$ mbar/year ${ }^{3}$ respectively. These findings demonstrate once again the sensitivity of coefficients to these short sub-sections of data near to the start and end of the records. At least, it can be seen that, in each pair of fits, the cubic coefficients are of the same sign and order of magnitude, indicating some similarity in century timescale variability.

If a genuine relationship between sea level and inverted air pressure at the gyre centre were to exist, then subtraction of the two series should identify periods of sea level variability due to other processes. It can be see from Fig. 3 that such a subtraction would identify primarily the two problematic sub-sections of data, together with a third spanning approximately two decades prior to 1900 . In the case of the early 19th century sea level data, there may be concerns as to data quality. However, the sea level values in recent decades, higher than those suggested by inverted air pressure, are particularly worthy of consideration as a genuine anomaly, given the quality of modern meteorological fields and tide gauge recording.

For comparison of the records at higher frequencies (i.e. interannual and decadal timescales), we made use of boxcar filters, requiring each box to contain a complete set of annual mean values; this method is clearly less suitable for study of low frequency behaviour given the data gaps. A maximum correlation of 0.495 was obtained with a filter full-width of 17 years, consistent with the findings of Sturges $(2009 a, b)$. Study of the relationships between sea level and air pressure (local, gyre centre and across the gyre) at such decadal timescales forms an important oceanographic research topic in itself. However, notwithstanding the remarks of Sturges (2009a, b), that century timescale variability forms only a small fraction of the total variance of the records, it is that particular aspect which has intrigued us most in the present investigation.

\section{Conclusions}

This exercise has been but one of many which are now demonstrating the value of data archaeology. In particular, reconstructed historical air pressure fields are now becoming available through advances in data rescue and advanced modelling (e.g. the Atmospheric Circulation Reconstructions over the Earth (ACRE) project, www.met-acre.org). The exercise has also demonstrated how much more can be learned when time series of more than one relevant parameter are available.
Our main scientific conclusion is that sea level on the eastern boundary of the North Atlantic does appear to be related on multi-decadal and century-timescales to the strength of the gyre-scale circulation, as represented by air pressure in the centre of the gyre. However, the conclusion is firmer if two sub-sections of data, at the start of the 19th century and in recent years, are omitted. This conclusion verifies to a great extent that of Miller and Douglas (2007) but with the use of a data set twice the length as that employed previously. It is also similar to that of Kolker and Hameed (2007) who determined that shifts in the positions and intensity of the major North Atlantic pressure centres (Azores High and Icelandic Low) could be drivers of a major fraction of the variability and trends in MSL on both sides of the ocean. However, that analysis was also restricted to the 20th century.

More work with the expanding data sets acquired via data archaeology will provide further insights. However, if the Miller and Douglas (2007) interpretation is on the right lines, then the sea level rise (fall) observed on the eastern boundary will be primarily a consequence of the spin down (up) response of the gyre to changes in wind stress curl. It follows that it will not then be related primarily to the changes in sea level that occur due to variations in ocean volume, although of course the different contributions to sea level change could be related indirectly through various climate forcings. In fact, given the extensive set of research into the reasons for sea level change (e.g. Bindoff et al., 2007), the Miller and Douglas (2007) proposition is not one that we necessarily subscribe to ourselves without further explanation being obtained through detailed ocean modelling. However, we do consider the proposition to be an intriguing one that merits more attention, hence our writing of this paper. It is certainly the case that the redistribution of water needs to be considered alongside the many factors responsible for ocean volume change on multi-decadal and century timescales that are included in periodic assessments such as that of Bindoff et al. (2007).

Acknowledgements. We thank Marcel Küttel of the University of Bern who first made us aware of the progress with the ship logbooks project. Bruce Douglas and Chris Hughes provided valuable comments and advice on the data analysis. In addition, we are very grateful to the two reviewers of the Discussion Paper (Professors Sturges and Tsimplis) for their remarks which may be read alongside the present paper. Nicolas Pouvreau acknowledges a postdoctoral fellowship funded by the Centre National d'Études Spatiales.

Edited by: E. J. M. Delhez 


\section{References}

Allan, R. and Ansell, T.: A new globally complete monthly historical mean sea level pressure data set (HadSLP2): 1850-2004, J. Climate, 19(22), 5816-5842, 2006.

Bindoff, N., Willebrand, J., Artale, V., Cazenave, A., Gregory, J., Gulev, S., Hanawa, K., Le Quéré, C., Levitus, S., Nojiri, Y., Shum, C. K., Talley, L., and Unnikrishnan, A.: Observations: oceanic climate change and sea level, in: Climate Change 2007: The Physical Science Basis. Contribution of Working Group 1 to the Fourth Assessment Report of the Intergovernmental Panel on Climate Change, edited by: Solomon, S., Qin, D., and Manning, M., Cambridge Univ. Press, New York, 2007.

Bouquet de la Grye, J-J.: Note sur le choix d'un zéro fondamental pour le nivellement, Ann. Hydrogr., 12, 32-38 (2ème série), 1890.

Gomis, D., Tsimplis, M. N., Martin-Miguez, B., Ratsimandresy, A. W., Garcia-Lafuente, J., and Josey, S. A.: Mediterranean Sea level and barotropic flow through the Strait of Gibraltar for the period 1958-2001 and reconstructed since 1659, J. Geophys. Res., 111(C11), C11005, doi:10.1029/2005JC003186, 2006.

Kolker, A. S. and Hameed, S.: Meteorologically driven trends in sea level rise, Geophys. Res. Lett., 34, L23616, doi:10.1029/2007GL031814, 2007.

Küttel, M., Xoplaki, E., Gallego, D., Luterbacher, J., GarcíaHerrera, R., Allan, R., Barriendos, M., Jones, P. D., Wheeler, D., and Wanner, H.: The importance of ship log data: reconstructing North Atlantic, European and Mediterranean sea level pressure fields back to 1750 , Clim. Dynam., doi:10.1007/s00382009-0577-9, 2009.

Leorri, E., Horton, B. P. and Cearetta, A.: Development of a foraminifera-based transfer function in the Basque marshes, $\mathrm{N}$. Spain: implications for sea-level studies in the Bay of Biscay, Mar. Geol., 251, 60-74, doi:10.1016/j.margeo.2008.02.005, 2008.

Luterbacher, J., Xoplaki, E., Dietrich, D., Jones, P. D., Davies, T. D., Portis, D., Gonzalez-Rouco, J. F., von Storch, H., Gyalistras, D., Casty, C., and Wanner, H.: Extending North Atlantic Oscillation reconstructions back to 1500 , Atmos. Sci. Lett., 2, 114-124, doi:10.1006/asle.2001.0044, 2002.
Miller, L. and Douglas, B. C.: Gyre-scale atmospheric pressure variations and their relation to 19th and 20th century sea level rise, Geophys. Res. Lett., 34, L16602, doi:10.1029/GL030862, 2007.

Pouvreau, N.: Trois cents ans de mesures marégraphiques en France: outils, méthodes et tendances des composantes du niveau de la mer au port de Brest, $\mathrm{PhD}$ thesis, University of La Rochelle, 2008.

Pouvreau, N., Martin Miguez, B., Simon, B., and Wöppelmann, G.: Evolution of sea-level components at Brest during the past 300 years, in preparation, 2010.

Sturges, T.: Interactive comment on "The gyre-scale circulation of the North Atlantic and sea level at Brest" by P. L. Woodworth et al., Ocean Sci. Discuss., 6, C724-C727, 2009.

Sturges, T.: Interactive comment on "The gyre-scale circulation of the North Atlantic and sea level at Brest" by P. L. Woodworth et al., Ocean Sci. Discuss., 6, C733-C735, 2009.

Tsimplis, M.: Interactive comment on "The gyre-scale circulation of the North Atlantic and sea level at Brest" by P. L. Woodworth et al., Ocean Sci. Discuss., 6, C894-C897, 2009.

Woodworth, P. L.: High waters at Liverpool since 1768: the UK's longest sea level record, Geophys. Res. Lett., 26(11), 1589-1592, 1999.

Woodworth, P. L., White, N. J., Jevrejeva, S., Holgate, S. J., Church, J. A., and Gehrels, W. R.: Evidence for the accelerations of sea level on multi-decade and century timescales, Int. J. Climatol., 29, 777-789, doi:10.1002/joc.1771, 2009a.

Woodworth, P. L., Teferle, N., Bingley, R., Shennan, I., and Williams, S. D. P.: Trends in UK mean sea level revisited, Geophys. J. Int., 176, 19-30, doi:10.1111/j.1365246X.2008.03942.x, 2009b.

Wöppelmann, G., Pouvreau, N., and Simon, B.: Brest sea level record: a time series construction back to the early eighteenth century, Ocean Dynam., 56, 487-497. doi:10.1007/s10236-0050044-z, 2006.

Wöppelmann, G., Pouvreau, N., Coulomb, A., Simon, B., and Woodworth, P.: Tide gauge datum continuity at Brest since 1711: France's longest sea-level record, Geophys. Res. Lett., 35, L22605, doi:10.1029/2008GL035783, 2008. 